\title{
Commentary
}

\section{Marriage, mortgage, motherhood: What longitudinal studies can tell us about gender, drug 'careers' and the normalisation of adult 'recreational' drug use}

\author{
Fiona Measham ${ }^{\mathrm{a}, *}$, Lisa Williams ${ }^{\mathrm{b}}$, Judith Aldridge ${ }^{\mathrm{b}}$ \\ a Department of Applied Social Science, Bowland College North, Lancaster University, Lancaster LA1 4YT, UK \\ b School of Law, University of Manchester, Oxford Road, Manchester M13 9PL, UK
}

\section{A R T I C L E I N F O}

\section{Article history:}

Received 12 October 2010

Received in revised form 14 April 2011

Accepted 7 June 2011

Available online $\mathrm{xxx}$

\section{Keywords:}

Gender

Longitudinal studies

Policy

Normalisation

Recreational drug use

Drug careers

\begin{abstract}
A B S T R A C T
Through a consideration of quantitative and qualitative data obtained from young women aged 18-28 in the later years of the North West England Longitudinal Study, this paper explores how women's drug careers develop, progressing the authors' normalisation thesis of 'recreational' drug use from adolescence into adulthood. Longitudinal studies are here compared with repeated cross-sectional surveys more usually favoured and funded by governments. The authors argue that firstly, in relation to methodology, longitudinal studies provide a unique opportunity to elucidate how drug careers develop across the life course and to chart the various impacts of life events and transitions on these careers and vice versa. Secondly, through this exploration of gender differences in drug careers and life transitions, we develop an age and gender-sensitive understanding of how recreational drug use fits into women's adult lives. The paper concludes that the challenge for policy makers is how to address adult women's 'normalised' recreational drug use, in the face of a regime focused on educational provision aimed at adolescent prevention; public health information designed for teenagers; and treatment resources focused on predominantly male and non parenting problem drug users, and the links between addiction and acquisitive crime.
\end{abstract}

(c) 2011 Elsevier B.V. All rights reserved.

\section{Introduction}

In the last two decades UK drug policy has increasingly focused on the drugs-crime relationship, through a prioritisation of the aims of control, crime prevention and coercion over those of health, harm reduction and individual voluntarism (Hough, 2001; Hunt \& Stevens, 2004; Reuter \& Stevens, 2008). Under the previous Labour government, a quasi-compulsory drug treatment programme drug tested those arrested for trigger offences, such as shop theft, and if they tested positive for heroin or cocaine, mandated treatment. Given that the UK has a higher proportion of male to female drug users in treatment (at a ratio of 3:1) and drug users coming through the offender pathway to treatment (NTA, 2010), compared to a 2:1 male to female ratio for drug users more generally (Hoare \& Moon, 2010 , p. 32), this policy disproportionately targets male 'problem drug users' and their links to acquisitive crime.

Female drug users have been neglected in policy responses which presume that drug users, particularly 'problem drug users', are male by default; female drug users can be cloaked by invisibility and the implications of policies for them are easily overlooked. If the 'drug problem' comes to be defined as men's problems, or indeed problems with men, then not only does it overlook about a third

\footnotetext{
* Corresponding author. Tel.: +44 01524 594106; fax: +44 01524592475.

E-mail address: F.Measham@lancaster.ac.uk (F. Measham).
}

of drug users, but where women's drug experiences differ from men's, they may receive less appropriate responses and resources. Although female drug users are as likely to access services and more likely to be parents in treatment (NTA, 2010), some women may feel excluded from services, particularly given the conflict of identity between drug use and motherhood, discussed further below. Furthermore, when women's drug problems do reach the attention of policy makers, or indeed the press, they are often defined by their gender: as mothers/future mothers, as sexual partners or sex workers (Ettorre, 2007).

From the 1980s, feminist methodologies have challenged positivist and quantitative methodologies dominated by 'malestream' academics (e.g. Harding, 1992; Stanley, 1990). As Taylor (1993) and Maher (1997) noted, male drug researchers have been more likely to research inner city 'hard' drug use and crime. Although since the 1990s, there has been an increasing focus by female drug researchers on women's use of ecstasy and other dance drugs, with an emphasis on women's agency, pleasure seeking, and broader leisure lifestyles (for review see Measham, 2002), qualitative studies are still favoured in research by women and about women (e.g. Henderson, 1999; Hutton, 2006). This is not to deny the feminist quantitative research tradition in the social sciences. Oakley has long advocated the case for feminist researchers to use mixed methods - including the rehabilitation of quantitative methods - arguing that the integration of a range of methods is necessary to create "an emancipatory social science" (1998, p. 707). 
Picking up this methodological debate, this paper argues firstly, for the unique potential of longitudinal studies to identify drug careers through an exploration of the relationship between starting, stopping and restarting drug use and key life transitions in early adulthood. Secondly, we consider the relevance of our normalisation thesis of adolescent 'recreational' drug use (Parker, Aldridge, \& Measham, 1998) to our longitudinal cohort after they reached adulthood, seeing how occasional and weekend drug use entwine with women's careers, parenting and domestic work. Whilst critics of the normalisation thesis have emphasised prevalence measures as a key determinant of the existence or otherwise of normalisation (Shiner \& Newburn, 1997); here and elsewhere (Aldridge, Measham, \& Williams, 2011) we instead emphasise the social and cultural acceptance of drugs in everyday lives. ${ }^{1}$ Finally, we conclude that qualitative and quantitative longitudinal data such as ours can be invaluable in informing gender-sensitive and feminist-driven policy.

\section{Comparing cross-sectional and longitudinal surveys}

Repeated cross-sectional surveys that produce 'trend' data, like the British Crime Survey in the UK (hereafter BCS), allow researchers to identify population level trends in drug taking, thus providing answers to questions such as whether the use of a particular drug is increasing, decreasing, or remaining stable. Surveys like these can provide policy makers with important information about fluctuations in the availability and preferences for specific drugs, such as the increasingly widespread use of cocaine powder documented by the BCS amongst young people from the late 1990 s to late 2000s (Hoare \& Moon, 2010). In contrast to crosssectional surveys - which question different samples of individuals over time - longitudinal surveys like the North West England Longitudinal Study (NWELS) follow the same sample of individuals over repeated surveys. This distinction is important. By tracking individuals, a longitudinal survey can address questions that simple trend data cannot: when drug use starts (onset) and stops (desistance), and other within-individual changes in drug taking. The drug use 'career' perspective - particularly useful for policy makers - is best investigated through longitudinal research. For example, a drug career perspective can help in understanding not only how drug taking may start, stop, and restart, but also how changes in frequency or intensity of use and types of drugs used may entail shifts between occasional, 'recreational', and more persistent or dependent use (Simpson, 2003). This feature of the longitudinal approach is especially useful for understanding how women's drug use is bound up in life transitions - for example, motherhood, marriage, employment or housing - considered below.

The advantages of longitudinal surveys, however, come at a cost, as our experience with the NWELS project illustrates. Longitudinal surveys are expensive to fund because of the substantial staff and other resource implications entailed in the time-consuming process of re-locating research participants at each stage. ${ }^{2}$ As well, cumulative attrition (loss) of the sample over successive surveys results in reduced - and less representative - sample sizes. In spite of our attempts to track carefully our research participants, and in some instances recapture those 'lost' (for a detailed discussion of

\footnotetext{
1 See Aldridge et al. (2011) for review of the normalisation thesis 1994-2011. 2 Although policy makers and funders are increasingly recognising the importance of longitudinal research to accumulating policy-relevant evidence (Bynner, 2010), the long-term funding commitment required means that studies like these remain the exception. Our approach with the NWELS was to cobble together finance from a range of funding agencies across the years. In total, six different tranches of funding were used from the first survey in 1991, with the most recent a three-year ESRC PhD studentship for the final follow-up when the cohort were 27/28 in 2005 (Williams, 2007).
}

the research methods used, see Aldridge et al., 2011), our final sample of 27/28 year olds was no longer representative of the sample at age 14 , and this attrition over time resulted in a disproportionate loss of male and more drug-involved respondents. Cross-sectional surveys thus offer population-representative understanding about drug taking across the age range whereas longitudinal studies can explore individual change over the life course. Policy is best informed by a range of research methodologies that each illuminates women's drug use more or less effectively. We turn now to a discussion of this issue in our consideration of cross-sectional and longitudinal studies.

\section{The gendering of general population surveys}

General population surveys (GPS) like the BCS have for decades documented a roughly 2:1 ratio of male to female drug users for most drugs (Hoare \& Moon, 2010). However, there is considerable evidence to suggest that the samples produced by the BCS are not representative of the general population from which they are drawn, and in particular, that they under-represent some kinds of drug taking. ${ }^{3}$ It seems likely too that gender will be involved in this under-representation, affecting our understanding of women's drug taking in policy-relevant ways.

There are growing concerns about social surveys: non-response has increased over the last two decades for the BCS and for social surveys internationally (Galea \& Tracy, 2007) causing concern about response bias. The European Monitoring Centre for Drugs and Drug Addiction has identified a falling response rate in European surveys; with disproportionate non-response rates from young people, drinkers and drug users; and the lack of an internationally standardised methodology (2009, p. 40). Although such surveys remain popular and publicly funded, falling response rates, non-response bias and public sector cuts in a climate of economic insecurity mean that their future is uncertain.

Even amongst survey responders, there may be non disclosure. Because of the greater stigma associated with female drug users, especially using mothers (Lloyd, 2010), gender may be implicated in willingness to disclose drug use, and thus in the validity of population estimates provided by GPS. The gender of the interviewer has long been demonstrated to affect responses to some kinds of interview questions. Respondents have been shown, for example, to be more willing to reveal 'non-traditional' responses to female interviewers (Flores-Macias \& Lawson, 2008). This kind of evidence suggests that we cannot discount the possibility that gender may influence the willingness of women to disclose drug taking, particularly when that drug taking is associated with stigma, or where respondents perceive that interviewers judge the circumstances of their lives as inappropriate to drug taking (for example, where respondents are mothers being interviewed at home and in the vicinity of children).

\footnotetext{
3 The BCS, like other household surveys, under-represents the most drug-involved populations for two reasons. Firstly, because the survey design excludes from the outset those who live in institutional settings like prisons, those who are homeless, and those who live chaotic or busy lives resulting in reduced opportunities for interview participation, it thus excludes groups more likely to be engaged in some types of drug use (see Hoare \& Moon, 2010). Secondly, because of the problem of non-response, it is not possible to understand exactly how those who decline to participate in the survey are different from those who do. Nevertheless, there is evidence that survey shortfalls exist for younger age groups and for men (Lynn \& Elliot, 2000; Van Loon, Tijhuis, Picavet, Surtees, \& Ormel, 2003), and amongst those living in areas of lower socio-economic status (Lynn \& Elliot, 2000), all factors associated with an increased likelihood of drug taking. Other research into non-response suggests that non-responders are more likely than responders to be heavy drinkers (Hill, Roberts, Ewings, \& Gunnell, 1997), smokers (Vink et al., 2004) and drug users (Cunradi, Moore, Killoran, \& Ames, 2005).
} 
Longitudinal surveys raise different visibility issues related to the problem of attrition. In the NWELS we know that attrition disproportionately affected men and the more drug-involved (Parker et al., 1998). One possible benefit of longitudinal research in relation to women's drug use, then, might be that we have stronger data for women than men because of gendered attrition rates. Equally the reverse may be true: whilst more men than women may be lost from longitudinal panels due to attrition, the women who are lost may disproportionately be more drug-involved. In other words, being a drug taker may 'trump' gender or the reverse; or a more complex interplay may be at work.

\section{Women's drug taking in the BCS}

We turn now to a sketch of women's drug taking gleaned from the BCS. Keeping in mind its limitations as discussed above, data like these are especially useful for identifying trends over time and group differences in drug taking. The 2009/10 BCS reports past year drug taking rates for women (5.4\%) at about half of that for men (11.9\%); and in spite of an overall decline in drug taking since 1996, the male:female ratio in past year drug use rates has remained roughly similar in the interim. Amongst some ethnic groupings however (e.g. black, Chinese, and 'mixed' ethnicities), these gender differences are less pronounced. Statistical techniques designed to identify the most important variables in understanding levels of drug use find gender (being male) amongst the four strongest predictors of past year drug taking, alongside age (being younger), alcohol consumption (more frequent) and marital status (being single). Many other apparently important predictors of drug taking (e.g. low household income, residing in urban areas) instead reflect more the characteristics of individuals residing in these households (that is, more likely to be male, younger, single).

It seems, therefore, that significant life transitions (e.g. marriage, growing older) are associated with differing levels of drug taking in the population, for both women and men. But how do these significant transitions exert their influence on individuals? Questions like this are best addressed using longitudinal research designs that allow within-individual changes to be examined. As we shall see, longitudinal approaches that combine both survey and in-depth qualitative data collection (like the NWELS) shed light on these questions in ways that GPS cannot.

\section{The NWELS: gender, drug careers and normalisation}

The data here comes from three key stages of the NWELS when the sample was aged 18,22 and 27/8. Data collected from the sample at age 27/28 formed part of Williams' doctoral research and analyses of the life transitions qualitative data is presented in her thesis and other publications (see Aldridge et al., 2011; Williams, in press). We present here for the first time analyses of quantitative data by gender and qualitative data relating to policy implications. Our analyses focus on the cohort at these times in their lives in order to capture key stages of transition. For most young people this decade coincides with considerable change: from adolescent to adult, away from the parental home, into job training and higher education, into long term relationships, and for some, parenthood. ${ }^{4}$ The methods for the research have been discussed in considerable detail elsewhere (see Aldridge et al., 2011; Williams, 2007). In brief, the study involved tracking a cohort of 14 year olds $(N=778)$ starting in 1991 , annually for five years, then again aged 22 in 1999, and aged 27/8 in 2004/5. The original cohort was derived from a cluster sample of eight state secondary schools in

4 The transitions within adolescence have been discussed in detail in Parker et al. (1998).
Table 1

Drug use status by gender at ages 18, 22 and 27 for NWELS.

\begin{tabular}{lllll}
\hline & & $\begin{array}{l}\text { Age 18 } \\
n=529 \\
\%\end{array}$ & $\begin{array}{l}\text { Age 22 } \\
n=465 \\
\%\end{array}$ & $\begin{array}{l}\text { Age 27 } \\
n=217 \\
\%\end{array}$ \\
\hline Current drug user & M & 51.6 & 61.9 & 59.8 \\
Drug desister & F & 41.3 & 44.4 & 46.5 \\
Drug abstainer & M & 20.5 & 17.3 & 11.5 \\
& F & 15.8 & 28.7 & 26.0 \\
& M & 32.7 & 20.8 & 28.7 \\
& F & 38.3 & 26.9 & 27.6 \\
\hline
\end{tabular}

Table 2

Lifetime, past year and past month prevalence of drug use by gender at ages 18, 22 and 27 for NWELS.

\begin{tabular}{lllll}
\hline & & $\begin{array}{l}\text { Age 18 } \\
n=529 \\
\%\end{array}$ & $\begin{array}{l}\text { Age 22 } \\
n=465 \\
\%\end{array}$ & $\begin{array}{l}\text { Age 27 } \\
n=217 \\
\%\end{array}$ \\
\hline Ever taken a drug & $\mathrm{M}$ & 66.5 & 79.2 & 71.3 \\
Taken a drug in & $\mathrm{F}$ & 60.7 & 73.2 & 72.4 \\
the past year & $\mathrm{M}$ & 58.0 & 61.7 & 34.1 \\
Taken a drug in & $\mathrm{F}$ & 49.2 & 45.0 & 34.1 \\
the past month & $\mathrm{M}$ & 44.6 & 39.1 & 20.0 \\
& $\mathrm{~F}$ & 28.2 & 25.2 & 19.2 \\
\hline
\end{tabular}

two metropolitan boroughs of Merseyside and Greater Manchester in North West England. Two schools in each borough had broadly working class catchment areas and two middle class. All data collection involved administering quantitative surveys. Additionally, in-depth interviews ${ }^{5}$ were conducted when the cohort were 17 , 22 and 28, ( $n=86$ aged 17, 86 aged 22 and 19 aged 28), and many of these involved repeated interviews with the same individuals, thus generating both qualitative and quantitative longitudinal data. The inevitable problems of attrition over the years mean that the samples aged 22 and 27 are not representative of the sample aged 14 , under-representing men, ethnic minorities, those from working class areas, and drug users; however, both samples aged 22 and 27 are roughly comparable with each other (see Aldridge et al., 2011).

We discuss here prevalence of drug use alongside drug status: abstainers (who have never taken a drug), current users (who have taken a drug in the past year) and desisters (who have not taken a drug in the past year) (Aldridge et al., 2011; Williams, 2007, in press).

\section{Drug use status, drug prevalence and gender}

Men were more likely to be current drug users at all ages compared to women (see Table 1), with women more likely to be drug abstainers or desisters. By age 27 , twice as many women as men were desisters.

Many respondents continued to take drugs in adulthood albeit less frequently. Lifetime rates of drug use over time are broadly similar between women and men in the sample with around threequarters having tried a drug by age 22 (see Table 2 ). For most illegal drugs the gender differences were small. Indeed the gender ratio is slightly smaller for this longitudinal data than for the BCS (see also Measham, 2002), suggesting that longitudinal studies are more successful than cross-sectional surveys at collecting data on women's drug use and/or that longitudinal studies suffer disproportionate attrition of male users. Women were less likely than men to be recent drug users in their late teens and early twenties; however, by 27 they were just as likely as men to be recent drug users. This

\footnotetext{
5 Purposive sampling was used in order to select respondents across the range of drug/alcohol using behaviours, and key demographic groups (see Aldridge et al., 2011 for more details).
} 
Table 3

Patterns of past month drug use by gender at ages 18, 22 and 27 for NWELS.

\begin{tabular}{|c|c|c|c|c|}
\hline Drugs taken in the past month: & & $\begin{array}{l}\text { Age } 18 \\
n=529 \\
\%\end{array}$ & $\begin{array}{l}\text { Age } 22 \\
n=465 \\
\%\end{array}$ & $\begin{array}{l}\text { Age } 27 \\
n=217 \\
\%\end{array}$ \\
\hline \multirow[t]{2}{*}{ Cannabis } & M & 39.3 & 32.7 & 12.6 \\
\hline & $\mathrm{F}$ & 25.9 & 20.7 & 14.2 \\
\hline \multirow[t]{2}{*}{ Amphetamines } & M & 11.2 & 4.6 & 0.0 \\
\hline & $\mathrm{F}$ & 8.5 & 3.0 & 0.8 \\
\hline \multirow[t]{2}{*}{ Ecstasy } & M & 10.3 & 12.6 & 3.5 \\
\hline & $\mathrm{F}$ & 5.9 & 5.3 & 6.3 \\
\hline \multirow[t]{2}{*}{ Cocaine } & M & 1.8 & 8.4 & 4.7 \\
\hline & $\mathrm{F}$ & 1.3 & 6.0 & 9.4 \\
\hline
\end{tabular}

\section{Table 4}

Prevalence of transitions to adulthood by gender at ages 18, 22 and 27 for NWELS

\begin{tabular}{|c|c|c|c|c|}
\hline & & $\begin{array}{l}\text { Age } 18 \\
n=529 \\
\%\end{array}$ & $\begin{array}{l}\text { Age } 22 \\
n=465 \\
\%\end{array}$ & $\begin{array}{l}\text { Age } 27 \\
n=217 \\
\%\end{array}$ \\
\hline In education & $\begin{array}{l}M \\
F\end{array}$ & $\begin{array}{l}62.0 \\
60.8\end{array}$ & $\begin{array}{l}32.5 \\
37.1\end{array}$ & $\begin{array}{r}6.8 \\
15.7\end{array}$ \\
\hline In employment & $\begin{array}{l}\mathrm{M} \\
\mathrm{F}\end{array}$ & $\begin{array}{l}35.7 \\
39.6\end{array}$ & $\begin{array}{l}82.7 \\
81.4\end{array}$ & $\begin{array}{l}97.7 \\
82.8\end{array}$ \\
\hline Living with parents & $\begin{array}{l}M \\
F\end{array}$ & $\begin{array}{l}85.4 \\
86.0\end{array}$ & $\begin{array}{l}58.0 \\
43.4\end{array}$ & $\begin{array}{l}26.1 \\
16.3\end{array}$ \\
\hline Living in rented accommodation & $\begin{array}{l}M \\
F\end{array}$ & - & $\begin{array}{l}3.1 \\
4.1\end{array}$ & $\begin{array}{l}13.6 \\
23.2\end{array}$ \\
\hline Living in own bought home & $\begin{array}{l}M \\
F\end{array}$ & - & $\begin{array}{c}7.35 \\
13.1\end{array}$ & $\begin{array}{r}4.5 \\
48.8\end{array}$ \\
\hline Single & $\begin{array}{l}M \\
F\end{array}$ & - & $\begin{array}{l}48.5 \\
32.2\end{array}$ & $\begin{array}{l}15.9 \\
17.1\end{array}$ \\
\hline Dating & $\begin{array}{l}M \\
F\end{array}$ & - & $\begin{array}{l}38.1 \\
38.2\end{array}$ & $\begin{array}{l}22.7 \\
16.3\end{array}$ \\
\hline Married/cohabiting & $\begin{array}{l}M \\
F\end{array}$ & - & $\begin{array}{l}19.5 \\
32.6\end{array}$ & $\begin{array}{l}61.3 \\
67.4\end{array}$ \\
\hline A parent & $\begin{array}{l}\mathrm{M} \\
\mathrm{F}\end{array}$ & - & $\begin{array}{l}4.1 \\
9.4\end{array}$ & $\begin{array}{l}12.5 \\
26.4\end{array}$ \\
\hline
\end{tabular}

illustrates a core feature of normalisation: that structural factors may not be the key predictor or protector from drug use.

There were few gender differences in the use of specific drugs over time (see Table 3). The drug most likely to have been tried ever, and recently, was cannabis, followed by stimulant drugs. There was a small self reported difference in past month stimulant drug preferences between women and men at 22: women were more likely to have taken cocaine, whereas for men it was ecstasy. When we follow the sample into their twenties we find similar patterns of drug use for women and men by age 27. Notably, women's past month use of cannabis, cocaine and ecstasy was higher than men's.

\section{Drug use status, transitions to adulthood and gender}

From age 18 onwards respondents were asked about their living arrangements, their education and employment status, their intimate partner relationships, and parenthood (see Table 4$).{ }^{6}$ These are discussed are discussed in the remainder of this paper in relation to gender and status as current drug users. We also turn to our qualitative data to provide a more nuanced account of the effect of life transitions upon drug journeys, particularly for our female respondents. We highlight the complexities of ordinary

\footnotetext{
${ }^{6}$ Data about intimate relationships and parenthood was not collected from the
} sample at age 18 . recreational drug use in adulthood, with fluctuations in frequency influenced by key life transitions. Some of our sample accommodated drug use into their lives whilst making key transitions. For others, these transitions became turning points in their drug journeys. As Vervaeke and Korf (2006) note, drug use declines for some when the demands of life increase.

\section{Leaving the parental home}

Over time respondents left the parental home and set up their own homes. Initially, interviewees reported feeling 'carefree'. They described being able to take drugs as often as they wished without arousing parental suspicion. In their twenties, male current users were more likely either to live with their parents or buy their own homes whereas female current users were more likely to be renting, with the potential housing insecurities that can result. As many bought their own homes or began living with a partner, the transition to independent living was seen as shifting from facilitating to hindering drug use. With increased financial responsibilities, some had less money to take drugs as frequently as they had previously. In addition, with the demands of housework, some female drug users noted that they had less time for drug taking:

"When you're getting in from work anywhere between, well half six on a good night or you know, anything up to eight, nine o'clock really, if we're busy at work. [... ] you've got the washing to do, your phone calls to make, tidying up, you know, you have all these things to do. And actually, when you've had a spliff it just makes you not wanna do anything." (Gaby, interview at age 28)

For this reason, some female drug users reduced the frequency of their drug use or completely stopped. Even a change of location for employment purposes became a turning point in some drug journeys:

"Me friends were moving down for their jobs and I got a job down here, and I thought well I'll just use this as a kind of break to stop taking it [cocaine] and me friends that I moved with they didn't use it or anything so I haven't taken it since." (Vicky, interview at age 28)

For Vicky and others, a change in location influenced their decision to stop taking drugs. In contrast, male drug users were more likely to remain living in the parental home. Notably only the male current drug users in our sample reported their parents permitted them to smoke cannabis in their bedrooms which might in part explain why they were more likely than female current users to be living with their parents in their twenties.

\section{Employment}

In their late teens male current drug users were more likely to be unemployed (15\%) compared to females (6\%); but by the late twenties differences in unemployment between male and female drug users had diminished substantially. For some, periods of unemployment had accompanied increases in drug consumption. Over time, the majority of the sample left education and gained full time employment, consistent with the observation by Vervaeke and Korf (2006) that employment places more demands upon drug users' time. Our interviewees perceived they had less time for drug taking once they were working full time. They noted, for example, that the recovery period after taking stimulant drugs affected their ability to function at work: 
“... I can't face the Tuesday after you've been out at the weekend, that's your real day that you feel so, 'Ugh, God!' Because it's just you can feel like that on a normal day when you've been at work, you know, you can feel so miserable and stressed out, that what's the point in making it worse by putting chemicals into your body? And, you know, sort of that's very much how I feel about it now. I've got no desire to go out and get fucked any more." (Gaby, interview at age 28)

The effect drug taking was perceived to have upon work performance was a reason many gave for stopping or reducing the frequency of their drug taking. With greater responsibilities at work, some moderated rather than stopped taking drugs in order to fulfil work commitments, a sign, we suggest, of normalisation:

“My work's getting quite stressful as well so I can't go out as much [and take drugs]. I feel cos I love my job that I don't want to be fucked when I'm doing it." (Natasha, interview at age 28)

We also found by age 27 almost twice as many female current users worked part time (10\%) compared to male drug users (6\%). A change in working hours could necessitate a change in drug use:

“Since I've had the [business] it can't affect it because I've got to be there everyday. [... ] Last time I was [interviewed] [... ] I was working half nine to half two so if you're thinking to yourself, 'Oh you've only got till half two and you can come home and go to sleep' then it didn't really affect it." (Stacey, interview at age 28)

Over time our female respondents were increasingly likely to work full time and have greater responsibilities at work as they progressed in their careers. Through the longitudinal study, we saw how this impacted upon drug careers for both women and men and how some chose to reduce the frequency of their drug taking or desist completely as their careers gained a higher priority in their lives.

\section{Intimate relationships}

As the sample matured, many settled into intimate relationships. By age 27, almost two-thirds were either married or living with a partner. Some gender differences emerged in respect of intimate relationships and drug status. By age 22, female current users were more likely to be dating (43\%) or cohabiting (25\%) compared to males ( $39 \%$ and $18 \%$ respectively), whilst male current users were more likely to be single (47\%) compared to females (36\%). These differences changed again at age 27: female current users were more likely to be cohabiting (51\%) compared to males (40\%) and more likely to be single compared to males ( $24 \%$ and $15 \%$ respectively); male current users were more likely to be dating (25\%) compared to females (14\%) and more likely to be married than females (19\% and $15 \%$ respectively). Relationship status was a further influence on their drug careers and for women played a significant role in providing access to drugs. These relationships often involved 'sorting' drugs; usually by men for women. Some of our female drug users described partners who provided them with access to drugs:

"I've never like actively gone out and bought cannabis ever, it's always been through a boyfriend - very rarely through friends, girlfriends." (Jan, interview at age 28)

Some female drug users also noted their consumption of drugs increased during the course of an intimate relationship:
"I probably should have just stayed with me friends because we used to just probably get a wrap's worth which had about a tenner's worth of speed in and we'd have a few, you know, a few dabs. ... and that would be it. Whereas with him [her partner], it just got silly." (Kate, interview at age 28)

Changes in drug journeys over the years were linked to changes in intimate relationships, such as partners reducing their drug use, or relationships ending. Typically, women in relationships with drug users also took drugs but stopped or slowed when these relationships ended and their access to drugs was limited. In contrast, male drug users rarely talked of accessing drugs via female partners and therefore relationship changes did not have the same impact on drug use.

\section{Parenthood}

Female current users were more likely to be parents (15\%) than males $(10 \%)$. When the impact of parenthood was explored with female interviewees, many stated it was the reason they no longer took drugs:

“Even since I've had her [her daughter] I've not really thought 'Oh, I can't wait to take cocaine again' cos I've not, I've not thought like that. She's my priority now and I'm glad to say it, it would never bother me if I never took anything again, it wouldn't. 'Cos I think if I did turn round to meself and say 'God, I can't wait until a week on Friday where I've got to have something' I wouldn't be a very good mum I don't think." (Stacey, interview at age 22)

In exploring with interviewees why motherhood led them to reduce or desist from drug use, some mothers described having less time to socialise and take drugs, whilst for others it was their identity as mothers that influenced their decisions. Stacey (above) believed she would not be a 'good mum' if she continued to take drugs. What seems to be at play here is a conflict of identities between aspiring to be a competent and responsible mother and being a drug user (see Banwell \& Bammer, 2006; Williams, 2007). As children became older, however, some parents recommenced their drug journeys. Having appropriate support networks and childcare options available to them were significant. Lindsay returned with her son Lloyd to live with her parents:

"[I] went back to my parents and then it was while I was at my parents [that I started taking cocaine again], you see, they used to go, 'You know, Linds, you go out luvvie', Lloyd would be in bed for half past six, 'You go out'." (Lindsay, interview at age 28)

We might have initially surmised from prevalence data that parenthood would lead to drug desistance, but our longitudinal qualitative data revealed a more complex picture. Whilst this transition clearly influenced the drug careers of our female users, it did not necessarily permanently curtail their drug use. After becoming parents, many returned to taking drugs, albeit less frequently than before, providing yet further evidence for normalisation in adulthood.

Three drug using mothers were interviewed twice in the later years of the NWELS: Lindsay, Stacey and Kate. When first interviewed, they had just become mothers and were not taking drugs but talked in detail about their former drug taking. All three were interviewed years later when their children were school aged. All had returned to taking drugs more frequently. They seemed comfortable discussing their drug taking with the interviewer (Williams), saying she was easy to talk to and non-judgemental. 
Whilst in part this may have been due to gender and interviewing style, no doubt the familiarity and trust built up over many years of a longitudinal study assisted the development of these mothers' openness about their continued drug use.

Our data suggests that by their late twenties many of our sample had negotiated key transitions to adulthood. They were living independently, working full time, had established intimate relationships, and a small proportion were parents. The significance of adult roles in reducing drug using behaviour has been noted by other drug researchers (Bachman, 1997; Kandel, 1980; Shiner, 2009; Vervaeke and Korf, 2006). Our qualitative data confirms how the adoption of adult roles became key turning points in drug careers and led some on the road to desistance. For others, their drug use was accommodated with the changing demands of their life, although often less frequently. Furthermore, we see the intersecting of these transitions, for example, with mothers returning to their parents with grandchildren and regaining some of the freedom to take drugs of their pre-parenthood lives. We now turn to consider the policy implications of our findings.

\section{Policy provision and gender-sensitive possibilities}

What are the policy implications of these women's drug careers we have charted through adolescence and into adulthood? Adult women's 'recreational' drug use takes place largely in a policy vacuum. We discuss here how female users fall through the education and treatment nets.

\section{(a) Drugs education, official and lay knowledge}

In the NWELS one of the first sources of drugs information was formal drugs education at school. In addition to this, some interviewees described how they sourced information about drugs from books (fictional and non-fictional), leaflets, websites and other media. For most, however, drug using friends were a key source of information and advice. Before trying a drug for the first time several of these sources may have been used. Many wanted to know what effect a drug might have on them:

"Before I took whizz [amphetamines] I found out about it, so I had an idea of what to expect and what it was doing to me." (Natasha, interview at age 22).

Over time, with growing experience of taking drugs, many of the sample believed they had acquired sufficient experiential knowledge and were less likely to seek advice from official drugs information sources. Indeed some expressed negative views about official sources: for example, the FRANK ${ }^{7}$ helpline was mocked:

"We all say on a Monday morning [after taking stimulant drugs at the weekend] 'Have you phoned FRANK?' (laughter) ... You know, FRANK? It's like an ongoing joke. Most people will come to my [workplace] on like a Monday morning and they're like 'Have you phoned FRANK yet?" (Stacey, interview at age 28)

Despite asserting that they had acquired lay knowledge of drugs through their own and friends' experiences and other sources of information, some female users did recall occasions which they described negatively, when they had taken too many drugs or the drugs they took did not have the desired effect.

\footnotetext{
${ }^{7}$ FRANK is a government funded helpline and website providing information
} about drugs aimed at young people.
"Last year when I was in [Cyprus] I had a bad E, a really, really bad one. I thought 'I could die here', I thought that I was dying. I said to me friend 'I'm saying bye now 'cos I'm dying' and she's like 'No way are you'. I thought I was dying. But I only took that on its own and I only took half. It was so strong, I've not took one since. I wouldn't, wouldn't dare. It's not put me off or anything it's just, I don't know, I was in a foreign country and it was like, I felt all paranoid and all shaky and everything. But, that was the only one and only time that l've ever felt like that and it did scare me a little bit. It did, I must admit." (Stacey, interview at age 22)

Re-interviewing Stacey aged 28, we found that she had recommenced her ecstasy use and was taking it most weekends.

Despite most of the sample considering themselves to be 'drugwise' (Parker et al., 1998) and describing in detail which drugs and how much to take for pleasure or for specific functions, some women were experiencing negative effects from taking drugs and were beginning to question their continued use:

"I'm not really too fussed [about taking stimulant drugs] any more. It takes me about three or four days to recover from it as well. (laughs) You just get - I just get absolutely knackered by it now. So I think I get to the point now where I think, 'Well is it really worth it for one day of running around like a dickhead? Is it worth it being shattered for like the next week?' So I'd rather now have a few glasses of wine and get a bit tipsy, you know, do that rather than be worn out." (Kate, interview at age 28)

Our research supports the view that after their early twenties most adults are no longer in touch with educational institutions; few are in touch with health or criminal justice agencies; and workplace policies focus on disciplinary interventions rather than support for drug using employees. The drugs education that they did receive, both as school children through educational institutions, and teenagers through FRANK, were prevention rather than harm reduction-oriented, poorly evaluated and an ineffective use of resources (Aldridge, 2008a). Thus experienced adult users (both male and female) like those in our sample rarely engage with 'official' information sources such as FRANK, seen as tailored to youthful experimentation rather than established adult use. Instead they place greater emphasis on lay and 'alternative' information of varying quality, such as drug-using friends and internet forums. Drawing on young adults' cyber-literate dispositions, recent campaigns that have attempted to utilise new social media for social marketing and health education purposes have to date tended to be unrealistic, inconsistent, non evidence-based, and thus largely ineffective (Atkinson et al., in press) What is needed instead are more adult-oriented, non judgemental and gender-sensitive information services (Aldridge, 2008b), including health campaigns that recognise the differential impact on women's health, reproductive system and social circumstances; as well as the relationship between gender, harm and pleasure in drug use (Ettorre, 1992).

\section{(b) Treatment}

In terms of treatment and service provision, UK policy has disproportionately focused on older, male, non parenting opiate users and the drugs-crime relationship in recent years (Reuter \& Stevens, 2008), with non opiate female users less likely to access services (Powis, Griffiths, Gossop, \& Strang, 1996). Additionally, because treatment resources are predominantly focused on the drugs/crime relationship, we find little available for adult women drug users whose drug use does not generate or drive acquisitive crime. We found no women in our sample who funded their 
(mostly moderate) drug taking through criminal activity; indeed, their drug taking was generally fitted around full or part time employment.

The Coalition government is set to target these same 'problem' user groups with its emphasis on residential rehabilitation and abstinence-based treatment programmes (Home Office, 2010). Such programmes are less relevant to the drug using patterns of our respondents - what were notably near-absent from the drug careers we observed were stories of addiction, overdose, offending and imprisonment. Whilst we recognise that not all 'recreational' drug use is non problematic (Aldridge, 2008b; Measham, Aldridge, \& Parker, 2001), the majority of adult women recreational users such as those in our sample do not want or need 'treatment', just access to advice and perhaps brief interventions on occasion. And if problems do emerge later in their drug careers, then participation in residential programmes could be potentially more problematic for women due to their greater caring responsibilities, lower income and insecurity in the housing market, potentially meaning less take-up of treatment. Indeed, many may not even bother to access treatment or face-to-face advisory services because of concerns about their conflicting identities as mothers and drug users (Marsh, D'Aunno, \& Smith, 2000). We would suggest that more gender-sensitive and parent-friendly services, offering enhanced access to a range of tailored treatment options, could have a significant positive impact.

\section{Conclusion}

Cross-sectional population surveys are able to provide population-representative understanding about drug taking across the age range. However, with declining response rates, nonresponse bias, unwillingness to disclose, and public sector funding cuts, we would argue that they are not - on their own - a sound basis for complex policy decisions. Longitudinal studies, by contrast, provide a unique opportunity to explore individual drug careers across the life course through the collection of qualitative and quantitative data not only on onset, desistance and recommencement of drug use, but also on changes in frequency or intensity of use, types of drugs used and patterns of consumption, contextualised in transitions from adolescence to adulthood. The NWELS tracked many hundreds of respondents from age 14 to 28 , and the richness of these data allows a deep understanding of the role of drugs in women's lives. Unlike GPS, the rapport between respondents and researchers that developed over the fourteen years of this project allowed some respondents, including drug using mothers, to feel able to confide in us about their drug use. Our respondents revealed the fine details of how their drug-taking decisions were made and remade, how occasional, weekend or more regular 'recreational' drug use fitted into their everyday lives and how these drug careers were affected by transitions such as leaving home, changing relationships, employment and parenthood.

Whilst women who marry, acquire mortgages and become mothers are all likely to have significantly lower levels of drug use in GPS, our longitudinal data goes beyond prevalence data to explore how such life transitions impact on those women who continue or recommence their drug use in adulthood and how they integrate drug use, more or less successfully, into their adult lives. We have shown how by their twenties, there were few gender differences in patterns of use amongst those who continue taking drugs, yet significantly more of our female drug users than male users were parents, lived in rented accommodation and lived independently of their own parents. For us, this is evidence of how gender interacts with 'normalised' adult drug use, with our female respondents facing greater challenges in how their drug use 'bedded in' in adulthood.
Yet women's recreational use remains largely invisible, takes place in a 'policy vacuum' and their needs with regard to drugs education, information and treatment service provision are not being met. We conclude that the challenges faced by female drug users, in terms of the gendering of drug careers, life transitions and caring roles, raise the broader question of whether we should strive for gender-neutral or gender-sensitive drug policy, bearing in mind that, to date, 'universal' in theory has meant male-oriented in practice.

\section{Acknowledgement}

Thanks to the three anonymous reviewers for comprehensive and constructive comments.

\section{References}

Aldridge, J. (2008a). A hard habit to break? A role for substance use education in the new millenium. Health Education, 108(3), 185-188.

Aldridge, J. (2008b). Decline but no fall? New millennium trends in young people's use of illegal and illicit drugs in Britain. Health Education, 108(3), 189-206.

Aldridge, J., Measham, F., \& Williams, L. (2011). Illegal leisure revisited. London: Routledge.

Atkinson, A., Sumnall, H., \& Measham, F. Depictions of alcohol use in a UK Government partnered online social marketing campaign: Hollyoaks 'The morning after the night before', Drugs: Education, Prevention, Policy, in press.

Banwell, C., \& Bammer, G. (2006). Maternal habits: Narratives of mothering, social position and drug use. International Journal of Drug Policy, 17, 504-513.

Bachman, J. G., Wadsworth, K. N., O’Malley, P. M., Johnston, L. D., \& Schulenberg, J. E. (1997). Smoking, Drinking and Drug Use in Young Adulthood: The Impacts of New Freedoms and Responsibilities. New Jersey: Lawrence Elbaum Associates.

Bynner, J. (2010). Editorial. Longitudinal and Life Course Studies, 1(2), 119-120.

Cunradi, C. B., Moore, R., Killoran, M., \& Ames, G. (2005). Survey nonresponse bias among young adults: The role of alcohol, tobacco, and drugs. Substance Use $\mathcal{E}$ Misuse, 40(2), 171-185.

Ettorre, E. (1992). Women and substance use. Basingstoke: Macmillan.

Ettorre, E. (2007). Revisioning women and drug use: Gender, power and the body. Basingstoke: Palgrave Macmillan.

European Monitoring Centre for Drugs and Drug Addiction. (2009). The state of drugs problem in Europe, Annual report. Lisbon: EMCDDA.

Flores-Macias, F., \& Lawson, C. (2008). Effects of interviewer gender on survey responses: Findings from a household survey in Mexico. International Journal of Public Opinion Research, 20(1), 100.

Galea, S., \& Tracy, M. (2007). Participation rates in epidemiologic studies. Annals of Epidemiology, 17(9), 643-653.

Harding, S. (Ed.). (1992). Feminism and methodology: Social science issues. Bloomington: Indiana University Press.

Henderson, S. (1999). Drugs and culture: The question of gender. In N. South (Ed.), Drugs: Cultures, controls and everyday life (pp. 36-48). London: Sage.

Hill, A., Roberts, J., Ewings, P., \& Gunnell, D. (1997). Non-response bias in a lifestyle survey. Journal of Public Health Medicine, 19(2), 203-207.

Hoare, J., Moon, D. (2010). Drug misuse declared: Findings from the 2009/10 British Crime Survey. Home Office: London.

Home Office. (2010). 2010 drug strategy consultation paper. Home Office: London. Available at: http://www.homeoffice.gov.uk/publications/consultations/consdrug-strategy-2010/drugs-consultation?view=Binary

Hough, M. (2001). Balancing public health and criminal justice interventions. International Journal of Drug Policy, 12, 429-433.

Hunt, N., \& Stevens, A. (2004). Whose Harm? Harm reduction and the shift to coercion in UK drug policy. Social Policy and Society, 3(4), 333-342.

Hutton, F. (2006). Risky pleasures? Club cultures and feminine identities. Aldershot: Ashgate.

Kandel, D. B. (1980). Drug and drinking behaviour among youth. Annual Review of Sociology, 6, 235-285.

Lloyd, C. (2010). Sinning and sinned against: The stigmatisation of problem drug users York: UK Drug Policy Commission.

Lynn, P., \& Elliot, D. (2000). The British Crime Survey: A review of methodology. London: National Centre for Social Research.

Maher, L. (1997). Sexed work: Gender, race, and resistance in a Brooklyn drug market. Oxford: Clarendon.

Marsh, J., D'Aunno, T., \& Smith, B. (2000). Increasing access and providing social services to improve drug abuse treatment for women with children. Addiction 95(8), 1237-1247.

Measham, F. (2002). 'Doing gender'-'doing drugs': Conceptualising the gendering of drugs cultures. Contemporary Drug Problems, 29(2), 335-373.

Measham, F., Aldridge, J., \& Parker, H. (2001). Dancing on drugs: Risk, health and hedonism in the British club scene. London: Free Association Books.

NTA. (2010). Women in drug treatment: What the latest figures reveal. London: National Treatment Agency. 
Oakley, A. (1998). Gender, methodology and people's ways of knowing: Some problems with feminism and the paradigm debate in social science. Sociology, 32, 707-731.

Parker, H., Aldridge, J., \& Measham, F. (1998). Illegal leisure: The normalisation of adolescent recreational drug use. London: Routledge.

Powis, B., Griffiths, P., Gossop, M., \& Strang, J. (1996). The differences between male and female drug users: Community samples of heroin and cocaine users compared. Substance Use and Misuse, 31(5), 529-543.

Reuter, P., \& Stevens, A. (2008). Assessing UK drug policy from a crime control perspective. Criminology and Criminal Justice, 8(4), 461-482.

Shiner, M. (2009). Drug Use and Social Change: The Distortion of History. Basingstoke: Palgrave Macmillan.

Shiner, M., \& Newburn, T. (1997). Definitely, maybe not? The normalisation of recreational drug use amongst young people. Sociology, 31(3), 511-529.

Simpson, M. (2003). The relationship between drug use and crime: A puzzle inside an enigma. International Journal of Drug Policy, 14, 307-319.

Stanley, L. (Ed.). (1990). Feminist praxis: Research, theory and epistemology in feminist sociology. London: Routledge.
Taylor, A. (1993). Women drug users: An ethnography of a female injecting community. Oxford: Clarendon.

Van Loon, A., Tijhuis, M., Picavet, H., Surtees, P., \& Ormel, J. (2003). Survey nonresponse in the Netherlands: Effects on prevalence estimates and associations. Annals of Epidemiology, 13(2), 105-110.

Vervaeke, H. K. E., \& Korf, D. J. (2006). Long-term ecstasy use and the management of work and relationships. International Journal of Drug Policy, 17, 484-493.

Vink, J. M., Willemsen, G., Stubbe, J. H., Middeldorp, C. M., Ligthart, R. S. L., Baas, K. D., et al. (2004). Estimating non-response bias in family studies: Application to mental health and lifestyle. European Journal of Epidemiology, 19(7), 623-630.

Williams, L. (2007). A lifecourse perspective on drug use from adolescence to adulthood: Onset, continuity, turning points and desistance. University of Manchester. Doctor of Philosophy. www.law.manchester.ac.uk/staff/lisa_williams.

Williams, L. Bridling the horse: Drug journeys from adolescence to young adulthood. Cullompton: Willan, in press. 